\title{
Early and late cranial ultrasonographic appearances and outcome in very low birthweight infants
}

\author{
R W I COOKE
}

Department of Child Health, University of Liverpool, Liverpool

SUMmARY Of 798 very low birthweight infants admitted to a regional neonatal intensive care unit over a five year period, 547 were discharged home and 524 available for follow up at two to five years later. Eighty-seven infants had a major impairment. Both early and late cerebral ultrasonographic appearances gave useful prognostic information, but the presence of cystic lesions, particularly if bilateral, was highly significant. There was a close correlation between late parenchymal lesions and previous ipsilateral intraventricular haemorrhage, suggesting a causal relation.

The introduction of cranial ultrasonography for diagnosing cerebral injuries has resulted in increased awareness of their frequency in very low birthweight infants and of their relevance in predicting neurodevelopmental outcome. Earlier studies emphasised the importance of periventricular haemorrhage. ${ }^{1-5}$ Parenchymal cystic lesions seen later in the neonatal period have recently been considered more important than haemorrhage in causing adverse outcome. ${ }^{67}$ Many of the studies on ultrasonographic appearances and follow up have comprised small numbers of patients or been done over short periods of time, thus not allowing a good estimate of the predictive value of ultrasonographic examination in the neonatal period. Studies have also not taken into account the effect of lesions on one or both sides of the brain, or the association between early haemorrhagic lesions and the later appearance of parenchymal cysts. These factors are important in making an accurate prognosis and attempting to prevent intraventricular haemorrhage.

\section{Patients and methods}

From January 1980 to December 1984, 798 infants weighing less than $1501 \mathrm{~g}$ at birth were admitted to this neonatal intensive care unit, and 547 were discharged home. No infants were excluded from the study. Seventeen infants subsequently died from various causes including the "sudden infant death syndrome', infections, non-accidental injury, and accidents. Of the remaining 530, $451(85 \%)$ were followed up at the regional unit, $53(10 \%)$ by consultant paediatricians at local hospitals, and the remainder by health visitors assessments, general practitioners' reports, or, in a few cases, questionnaire to the parents. The duration of follow up varied between two and five years.

Follow up at the regional centre comprised neurological and general physical examination, together with developmental screening with the Denver developmental screening test at 1 year and annually thereafter. Specialist referral to the

Table 1 Classification of early and late ultrasonographic appearances

\begin{tabular}{|c|c|}
\hline Grade & Description \\
\hline \multicolumn{2}{|l|}{ Early lesions } \\
\hline 0 & Normal \\
\hline Flare & $\begin{array}{l}\text { Small, often transient echodensities } \\
\text { at upper border of lateral } \\
\text { ventricles }\end{array}$ \\
\hline 1 & Subependymal haemorrhage \\
\hline 2 & Intraventricular haemorrhage \\
\hline 3 & $\begin{array}{l}\text { Parenchymal haemorrhage or } \\
\text { extension }\end{array}$ \\
\hline \multicolumn{2}{|l|}{ Late lesions } \\
\hline 0 & Normal \\
\hline $\begin{array}{l}\text { Persistent ventricular } \\
\text { enlargement }\end{array}$ & $\begin{array}{l}\text { Usually irregular or asymetrical, } \\
\text { beyond } 1 \text { month of age. }\end{array}$ \\
\hline $\begin{array}{l}\text { Periventricular } \\
\text { leucomalacia }\end{array}$ & $\begin{array}{l}\text { Periventricular cysts, usually } \\
\text { multiple and small and not } \\
\text { connecting with the ventricle }\end{array}$ \\
\hline Porencephalic cysts & $\begin{array}{l}\text { Large, usually solitary cysts seen } \\
\text { often after previous infarction or } \\
\text { parenchymal extension of } \\
\text { haemorrhage }\end{array}$ \\
\hline
\end{tabular}


regional child development centre was made if neurodevelopmental problems were detected. Impairment was defined as a developmental quotient of $<80$. cerebral palsy of any degree, or hearing or visual loss likely to impair developmental progress. Severe developmental delay was considered to be equivalent to a developmental quotient of 5) or less, and moderate developmental delay was a developmental quotient of 51-80. Four children had chromosomal disorders or syndromes, and two were severely impaired postnatally by non-accidental injury and excluded from this analysis. The follow up assessments are the result of pooled reports from several sources for some cases.

All infants had a cranial ultrasonographic examination on admission to the unit, daily for the first week of life, and weekly or more often until discharge. Ultrasonography was performed by me or by a lecturer or research fellow supervised by me. The time of the babies' discharge varied, but those discharged early often had ultrasonographic examinations at their first or second follow up visit,
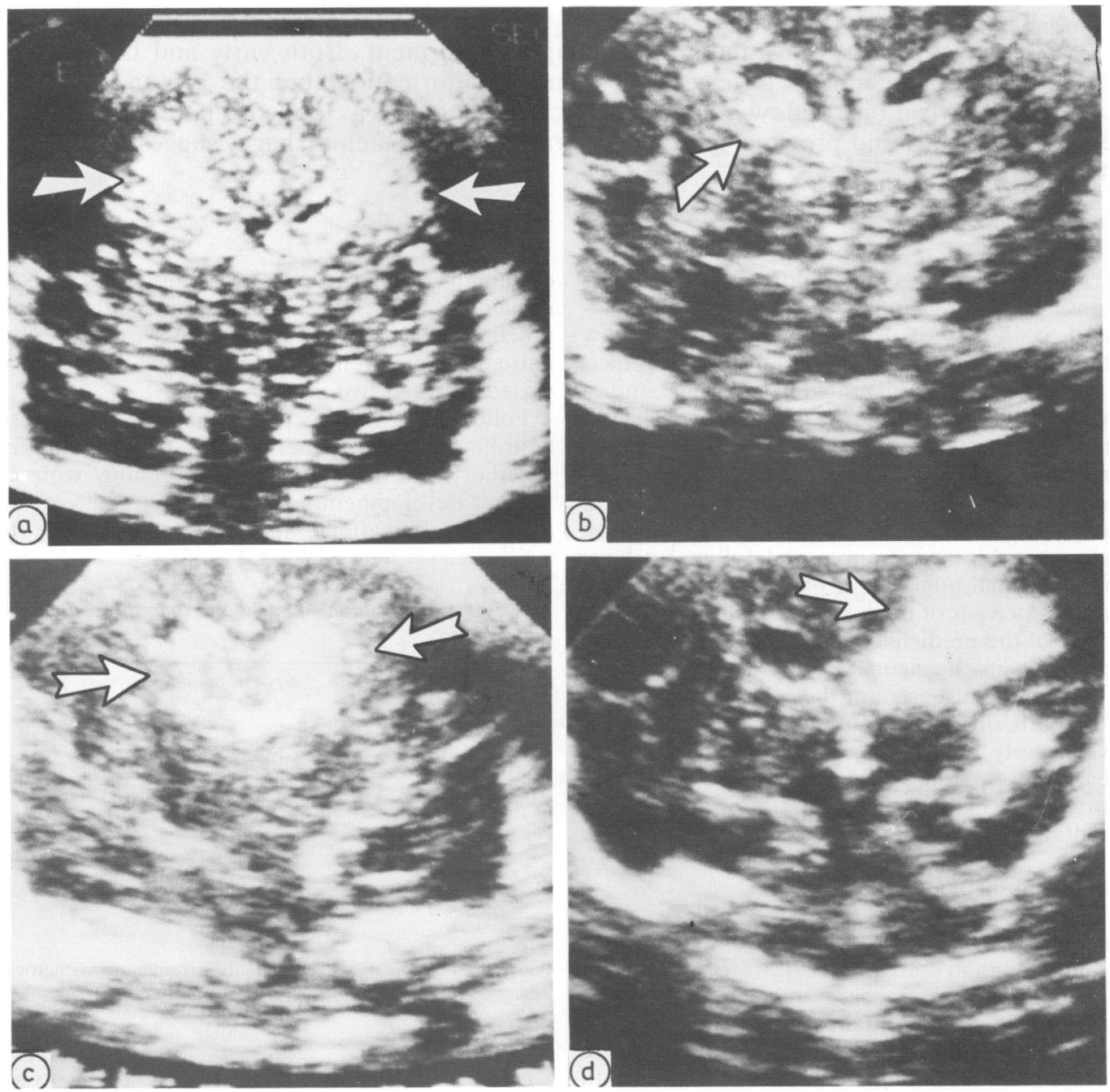

Fig. 1a Early ultrasound appearances: bilateral 'flares'. Fig. 1b Early ultrasound appearances: unilateral subependymal haemorrhage (grade 1). Fig. 1c Early ultrasound appearances: bilateral intraventricular haemorrhage (grade 2). Fig. 1d Early ultrasound appearances: unilateral parenchymal haemorrhage (grade 3). 
but only if previous abnormalities had been detected. Infants weighing $<1500 \mathrm{~g}$ at birth were rarely discharged at less than 2 weeks of age, and usually much later. All babies referred from other hospitals were admitted before the third day of life and most of them on the day of birth. An Advanced Technology Laboratories (ATL) 805A mechanical sector scanner with 5 or $7.5 \mathrm{MHz}$ transducers was used. A written record of each examination was kept together with Polaroid photographs of changes as they occurred. Appearances were designated 'early', representing mainly haemorrhagic lesions and occurring during the first week of life, and 'late', representing parenchymal lesions probably due to cerebral ischaemia or atrophy and first visible from the second week onwards. Table 1 shows the classification, which is illustrated in figs 1 and 2 . Only coronal sections are shown, but sections in the midline, parasaggital, and tangential parasaggital planes were also used to complete the diagnosis. Differences in proportions of impairments with different ultrasonographic appearances were analysed with the $\chi^{2}$ test unless otherwise stated, and a probability of $<0.05$ was accepted as significant.

\section{Results}

Five hundred and twenty-four infants were available

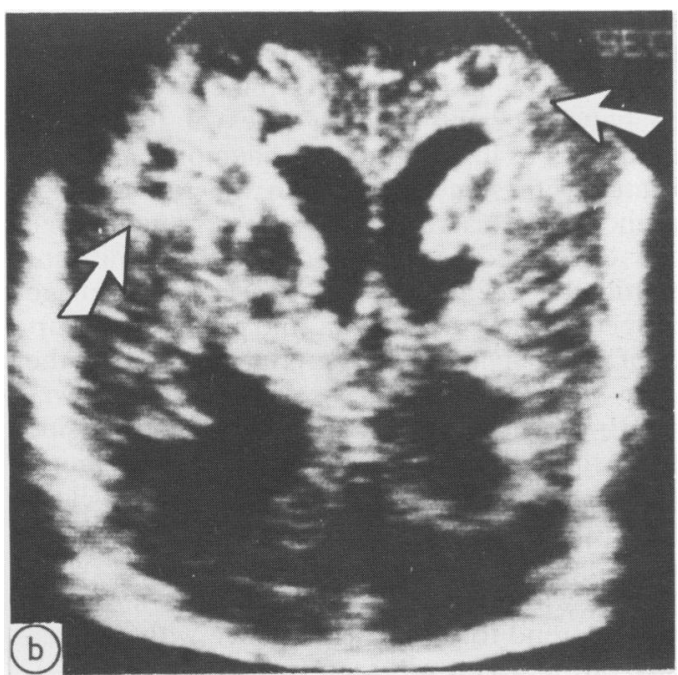

Fig. 2a Late ultrasound appearances: perisistent ventricular enlargement.

Fig. $2 \mathrm{~b}$ Late ultrasound appearances: periventricular leucomalacia.

Fig. 2c Late ultrasound appearances: porencephalic cyst. 
for follow up, and information from at least one source was available on all of them. Of these, 87 infants had an impairment; 50 had cerebral palsy, 39 had moderate developmental delay, 17 had severe developmental delay, 12 were blind (six from retinopathy and six with presumed cortical blindness), 11 had bilateral severe deafness, and 12 had epilepsy. Several infants had more than one impairment.

When early ultrasonographic appearances were correlated with later impairment a significant trend to greater prevalence of impairment was seen with increasing grades of haemorrhage, $(p<0.001$, table 2). Table 2 also shows the $95 \%$ confidence intervals for the prevalence of impairment in each ultrasound group. Bilateral grade 2 or 3 haemorrhage in the first week of life is more likely to result in impairment (table 1). Different grades of haemorrhage were almost exactly symmetrically distributed between right and left sides of the brain. Minor as well as major grades of haemorrhage were associated with some increase in the risk of later impairment, but this was usually because parenchymal lesions developed later. There was a significant correlation between the grade of early haemorrhage not affecting the parenchyma and the later occurrence of parenchymal lesions on the same side of the brain ( $p<0.001$, table 3$)$. No such correlation was seen with parenchymal lesions on the opposite side of the brain. This suggests a causal association between early haemorrhage and the later development of ipsilateral parenchymal lesions.

When late ultrasonographic appearances were correlated with subsequent impairments a similar significant trend to greater prevalence with increasing size of the lesion was seen $(p<0.001$, table 4$)$.
Periventricular leucomalacia was first seen at a median of 15 days (range 4-50 days $n=47$ ). Bilateral cystic lesions (periventricular leucomalacia or porencephalic cysts) greatly increase the risk of impairment. Most infants with impairments at follow up had either cerebral palsy or moderate or severe developmental delay.

Developmental delay was significantly associated with cystic lesions $(p<0.001)$ particularly when they occurred bilaterally rather than unilaterally (Fisher's exact test, $p<0.004$ ) (table 4). Similar associations were seen with cerebral palsy. Porencephalic cysts were more likely to result in cerebral palsy than periventricular leucomalacia. The incidence of cerebral palsy after bilateral lesions of any sort was higher than that after unilateral lesions. Evidence of early haemorrhage, and late ultrasonographic appearances, had similar sensitivi-

Table 3 Association between early periventricular haemorrhage and late parenchymal lesions on ipsilateral side of brain

\begin{tabular}{|c|c|c|c|}
\hline & \multirow[t]{2}{*}{0} & \multicolumn{2}{|c|}{ Late parenchymal lesions } \\
\hline & & $\begin{array}{l}P V E \\
\text { No }(\%)\end{array}$ & $\begin{array}{l}\text { Cystic }(P V L \text { and } P C) \\
\text { No }(\%)\end{array}$ \\
\hline \multicolumn{4}{|c|}{$\begin{array}{l}\text { Grade of } \\
\text { haemorrhage }\end{array}$} \\
\hline 0 & 372 & $(2 \%)$ & $(2 \cdot 5 \%)$ \\
\hline 1 & 48 & $(8 \cdot 5 \%)$ & $(10 \%)$ \\
\hline 2 & 43 & $(21 \%)$ & $(27 \%)$ \\
\hline
\end{tabular}

PVE $=$ Persistent ventricular enlargement

PVL $=$ Periventricular leucomalacia .

$\mathrm{PC}=$ Porencephalic cyst.

Table 2 Early ultrasound appearances and major impairments

\begin{tabular}{|c|c|c|c|c|c|c|c|}
\hline Diagnosis & $\begin{array}{l}0 \\
(n=3.3 .3)\end{array}$ & $\begin{array}{l}\text { Flare } \\
(n=1.3)\end{array}$ & $\begin{array}{l}l \\
(n=73)\end{array}$ & $\begin{array}{l}\text { haemorrhage } \\
2 \\
(n=73)\end{array}$ & $\begin{array}{l}3 \\
(n=32)\end{array}$ & $\begin{array}{l}\text { Unilateral } \\
2 \text { or } 3 \\
(n=56)\end{array}$ & $\begin{array}{l}\text { Bilateral } \\
3 / 2 \text { or } 3 / 3 \\
(n=11)\end{array}$ \\
\hline Normal & 314 & 12 & 59 & 43 & 9 & 32 & 2 \\
\hline $\begin{array}{l}\text { Moderate DD } \\
(\text { DO }<80)\end{array}$ & $\begin{array}{l}11 \\
(3 \cdot 3 ; 1 \cdot 8-6 \cdot 5)\end{array}$ & 0 & $\begin{array}{l}6 \\
(8 \cdot 2 ; 3 \cdot 2-17 \cdot 7)\end{array}$ & $\begin{array}{l}11 \\
(15 ; 7 \cdot 5-24 \cdot 7)\end{array}$ & $\begin{array}{l}11 \\
(34: 18 \cdot 6-53 \cdot 2)\end{array}$ & $\begin{array}{l}10 \\
(18 ; 9-30 \cdot 9)\end{array}$ & $\begin{array}{l}4 \\
(36 ; 10 \cdot 9-69 \cdot 3)\end{array}$ \\
\hline $\begin{array}{l}\text { Severe DD } \\
(\text { DQ }<50)\end{array}$ & $\begin{array}{l}2 \\
(0 \cdot 6 ; 0 \cdot 08-2 \cdot 4)\end{array}$ & 0 & $(4 \cdot 1: 0 \cdot 9-12)$ & $\begin{array}{l}4 \\
(10 \cdot 9: 5-21 \cdot 3)\end{array}$ & $\begin{array}{l}6 \\
(12 \cdot 5 ; 3 \cdot 5-29)\end{array}$ & $\begin{array}{l}2 \\
(10 \cdot 7 ; 4 \cdot 1-22 \cdot 2)\end{array}$ & $(18 \cdot 1 ; 2 \cdot 3-51 \cdot 8)$ \\
\hline $\begin{array}{l}\text { Cerebral } \\
\text { palsy }\end{array}$ & $\begin{array}{l}10 \\
(3 \cdot 6: 1 \cdot 6-6 \cdot 0)\end{array}$ & 1 & $\begin{array}{l}6 \\
(8 \cdot 2 ; 3 \cdot 2-17 \cdot 7)\end{array}$ & $\begin{array}{l}13 \\
(17 \cdot 8: 9 \cdot 6-27 \cdot 8)\end{array}$ & $\begin{array}{l}20 \\
(62 \cdot 5 ; 43 \cdot 7-78 \cdot 8)\end{array}$ & $\begin{array}{l}15 \\
(26 \cdot 8 ; 15 \cdot 9-4() \cdot 6)\end{array}$ & $\begin{array}{l}9 \\
(81 \cdot 8 ; 48 \cdot 2-97 \cdot 7)\end{array}$ \\
\hline Deaf & 0 & 0 & 2 & 5 & 4 & 4 & 1 \\
\hline Blind & 1 & 0 & 1 & 8 & 2 & 4 & 1 \\
\hline $\begin{array}{l}\text { Any major } \\
\text { impairments }\end{array}$ & $\begin{array}{l}19 \\
(5 \cdot 7: 3 \cdot 6-9 \cdot 3)\end{array}$ & $\begin{array}{l}1 \\
(7 \cdot 7 ; 0 \cdot 2-36)\end{array}$ & $\begin{array}{l}14 \\
(19 \cdot 2 ; 10 \cdot 9-29 \cdot 7)\end{array}$ & $\begin{array}{l}30 \\
(41 \cdot 1: 29 \cdot 7-52 \cdot 9)\end{array}$ & $\begin{array}{l}23 \\
(71 \cdot 9 ; 57 \cdot 5-83 \cdot 7)\end{array}$ & $\begin{array}{l}24 \\
(42 \cdot 8: 29 \cdot 7-57 \cdot 0)\end{array}$ & $\begin{array}{l}9 \\
(81 \cdot 8: 48 \cdot 2-97 \cdot 8)\end{array}$ \\
\hline
\end{tabular}

Figures in parentheses are percentage incidence and $95 \%$ confidence intervals for each group. $\mathrm{DD}=$ development delay.

DQ $=$ developmental quotient. 
Table 4 Later ultrasound appearances and major impairments

\begin{tabular}{|c|c|c|c|c|c|c|}
\hline \multirow[b]{2}{*}{ Diagnosis } & \multirow[b]{2}{*}{$\begin{array}{l}0 \\
(n=418)\end{array}$} & \multirow[b]{2}{*}{$\begin{array}{l}\text { Persistent } \\
\text { ventricular } \\
\text { enlargement } \\
(n=40)\end{array}$} & \multicolumn{2}{|c|}{ Ultrasound appearances } & \\
\hline & & & $\begin{array}{l}\text { Periventricular } \\
\text { leucomalacia } \\
(n=34)\end{array}$ & $\begin{array}{l}\text { Porencephalic } \\
\text { cyst } \\
(n=32)\end{array}$ & $\begin{array}{l}\text { Cystic lesions }(P V \\
\text { Unilateral } \\
(n=42)\end{array}$ & $\begin{array}{l}L \text { and } P C) \\
\text { Bilateral } \\
(n=24)\end{array}$ \\
\hline Normal & 382 & 32 & 16 & 7 & 20 & 3 \\
\hline $\begin{array}{l}\text { Moderate DD } \\
(\mathrm{DQ}<8(0))\end{array}$ & $\begin{array}{l}16 \\
(3 \cdot 8 ; 2 \cdot 2-6 \cdot 8)\end{array}$ & $\begin{array}{l}4 \\
(10 ; 2 \cdot 8-23 \cdot 7)\end{array}$ & $\begin{array}{l}10 \\
(29 \cdot 4 ; 19 \cdot 1-41 \cdot 6)\end{array}$ & $\begin{array}{l}9 \\
(28 \cdot 1 ; 13 \cdot 7-46 \cdot 7)\end{array}$ & $\begin{array}{l}12 \\
(28 \cdot 6 ; 15 \cdot 7-44 \cdot 6)\end{array}$ & $\begin{array}{l}7 \\
(29 \cdot 2 ; 12 \cdot 6-51)\end{array}$ \\
\hline $\begin{array}{l}\text { Severe DD } \\
(\mathrm{DQ}<5())\end{array}$ & $(1 \cdot 2 ; 0 \cdot 3-2 \cdot 5)$ & () & $(11 \cdot 8 ; 3 \cdot 2-26 \cdot 7)$ & $(25 ; 11 \cdot 5-43 \cdot 4)$ & $\begin{array}{l}1 \\
(2 \cdot 4 ; 0 \cdot(06-13 \cdot 1)\end{array}$ & $\begin{array}{l}11 \\
(45 \cdot 8 ; 25 \cdot 6-67 \cdot 2)\end{array}$ \\
\hline $\begin{array}{l}\text { Cerebral } \\
\text { palsy }\end{array}$ & 17 & $\frac{5}{(12 \cdot 5 ; 4 \cdot 2-26 \cdot 8)}$ & $(17 \cdot 6: 6 \cdot 5-33 \cdot 6)$ & $\begin{array}{l}22 \\
(68 \cdot 7 ; 5()-83 \cdot 8)\end{array}$ & $(30 \cdot 9 ; 17 \cdot 6-47)$ & $\begin{array}{l}15 \\
(62 ; 40 \cdot 6-81 \cdot 2)\end{array}$ \\
\hline Deaf & 4 & 1 & 3 & 3 & 6 & 0 \\
\hline Blind & 3 & 0 & 5 & 4 & 1 & 8 \\
\hline $\begin{array}{l}\text { Any major } \\
\text { impairments }\end{array}$ & $\begin{array}{l}36 \\
(8 \cdot 6 ; 6 \cdot 4-12 \cdot 2)\end{array}$ & $\begin{array}{l}8 \\
(20 ; 9-36)\end{array}$ & $\begin{array}{l}18 \\
(52 \cdot 9: 35-70)\end{array}$ & $\begin{array}{l}25 \\
(78 \cdot 1 ; 60-91)\end{array}$ & $\begin{array}{l}22 \\
(52 \cdot 4 ; 1-66 \cdot 6)\end{array}$ & $\begin{array}{l}21 \\
(87 \cdot 5 ; 66 \cdot 6-97 \cdot 3)\end{array}$ \\
\hline
\end{tabular}

Figures in parentheses are percentage incidence and $95 \%$ confidence intervals for each group.

$\mathrm{DD}=$ development delay: PVL = periventricular leucomalacia; PL = porencephalic cyst; DQ = developmental quotient.

Table 5 Sensitivity and specificity of early and late ultrasound appearances in predicting later impairments

\begin{tabular}{|c|c|c|c|c|c|c|}
\hline & \multicolumn{2}{|l|}{ All impairments } & \multicolumn{2}{|c|}{ Severe developmental delay } & \multicolumn{2}{|l|}{ Cerebral palsy } \\
\hline & Sensitivity $(\%)$ & Specificity $(\%)$ & Sensitivity (\%) & Specificity $(\%)$ & Sensitivity $(\%)$ & Specificity $(\%)$ \\
\hline $\begin{array}{l}\text { Grade } 2 \\
\text { or } 3 \mathrm{PVH}\end{array}$ & 61 & 92 & 71 & 82 & 66 & 96 \\
\hline $\begin{array}{c}\text { Late cystic lesion } \\
(\text { PVL or PC) }\end{array}$ & 49 & 9() & 70 & 99 & 56 & 95 \\
\hline
\end{tabular}

$\mathrm{PVH}=$ periventricular haemorrhage; $\mathrm{PVL}=$ periventricular leucomalacia; $\mathrm{PC}=$ porencephalic cyst.

Table 6 Types of cerebral palsy and ultrasound lesions observed

\begin{tabular}{llll}
\hline & $\begin{array}{l}\text { No ultrasound } \\
\text { lesions }\end{array}$ & PVH only & $\begin{array}{l}\text { Late ultrasound } \\
\text { lesions }\end{array}$ \\
\hline $\begin{array}{c}\text { Diplegia } \\
(\mathrm{n}=15)\end{array}$ & 6 & 4 & 5 \\
$\begin{array}{c}\text { Hemiplegia } \\
(\mathrm{n}=26)\end{array}$ & 2 & 3 & 21 \\
$\begin{array}{c}\text { Quadriplegia } \\
\text { and others } \\
(\mathrm{n}=9)\end{array}$ & 1 & 1 & 7 \\
\hline
\end{tabular}

PVH $=$ periventricular haemorrhage.

ties and specificities in predicting impairments (table 5). Spastic diplegia $(n=15)$ was more often seen in infants without late ultrasonographic abnormalities, whereas hemiplegia $(n=26)$ and quadriplegia $(n=9)$ were usually associated with late parenchymal lesions. This difference was significant (Fisher's exact test $p<0 \cdot 0045$, table 6).

\section{Discussion}

When portable ultrasonography machines became available to neonatologists less than 10 years ago they replaced computed axial tomography as the main method of diagnosing cerebral haemorrhagic and ischaemic lesions because less invasive and more frequent examinations could be made. The first reports concentrated on the incidence of periventricular haemorrhage and factors associated with its occurrence. ${ }^{18-10}$ Subsequent studies concentrated on the association between the early findings of haemorrhage and outcome. $.^{2-5} 11-12$ In some of these studies 'outcome' concerned early death rather than developmental progress in later years, and in others the small number of subjects studied did not allow confident prediction of outcome. In similar groups of very low birthweight infants conclusions such as that all parenchymal haemorrhages are fatal, ${ }^{5}$ smaller haemorrhages are not associated with poorer outcome, ${ }^{11}$ smaller haemorrhages are associated with poorer outcome, ${ }^{5}$ and ventricular dilatation ${ }^{13}$ or parenchymal cystic 
lesions ${ }^{67}$ are the main determinants of outcome may all be found.

To assemble sufficient numbers of infants for examination of outcome by subgroups an investigation such as this must continue over several years in a large centre. This produces several methodological problems. Ultrasonographic equipment is constantly improving. For the first three and a half years of the period covered by this study a $5 \mathrm{MHz}$ transducer was used; subsequently a $7.5 \mathrm{MHz}$ transducer was used with theoretically, better linear resolution. The proportion of infants with areas of cystic degeneration diagnosed remained substantially the same in each year of the study, although more 'flares' were noted later in the study. The interpretation of results also changed over the five year period, periventricular leucomalacia being recorded as 'cerebral atrophy' or 'irregular ventricles' in the early part of the study and a four point scale of severity for periventricular haemorrhage being used. With the publication of pathological correlation studies the nomenclature used in this paper was adopted, and previous ultrasonographic pictures were reclassified using the Polaroid records and the contemporary written reports.

Infants with impairments seen at follow up comprised $10 \%$ of the original group admitted to the unit, and most had ultrasonographic abnormalities in the perinatal period. Whether early or late ultrasonographic appearances are used as predictors of later impairment, the sensitivity and specificity are similar (table 5). This is important, as if this information is to be taken into account when making clinical decisions about management it is required early rather than late in the neonatal period. The occurrence of later impairments in infants with early lesions not affecting the parenchyma seems to be associated almost entirely with the subsequent development of periventricular leucomalacia. That a significant relation exists between the extent of early and late appearances in the same infant, but only when the same side of the brain is considered, is strongly suggestive that this association is causal (table 3 ). The release of vasoactive substances by thrombi produced from early periventricular haemorrhage may produce local ischaemia and late periventricular leucomalacia. Preventing periventricular haemorrhage, or blocking the release or effects of substances released from thrombi, may limit the development of subsequent lesions and their neurodevelopmental sequelae. Severe local cerebral ischaemia at the site of previous cerebral haemorrhage has been shown by positron emission tomography. ${ }^{14}$

Because of the number of infants included in this study it was possible to consider the predictive value of ultrasonographic appearances for specific neurodevelopmental problems rather than for major problems generally. The presence of late cystic lesions was strongly predictive of developmental delay, and this association was more obvious when the lesions were bilateral. Bilateral lesions were more than twice as likely to be followed by developmental delay as unilateral ones, but, more importantly, in most of these cases the impairment was severe (table 4). The severe effect of bilateral lesions on intellectual prognosis may simply be related to the extent of the original brain injury, or be because both sides of the neonatal brain possess cognitive functions which may in part be preserved in unilateral lesions.

The prevalence of cerebral palsy should correlate well with cerebral ultrasonographic findings, particularly late cystic changes. Of the 50 infants with cerebral palsy at follow up, $33 \%$ had late lesions, which suggested that they had been caused by perinatal events. In nine infants, however, no ultrasonographic abnormalities were seen. This could be because the abnormalities were beyond the resolution of the machine used, or because they occurred after the infants had been discharged from the unit. Alternatively, cerebral palsy may in some cases be caused by aetiological events outside the perinatal period. Support for the latter view comes from the distribution of late ultrasonographic lesions between types of cerebral palsy. Cystic appearances were strongly associated with spastic hemiplegia and quadriplegia but significantly less so with spastic diplegia, suggesting different aetiologies. The median length of stay of the 15 infants with spastic diplegia was 40 days (range 11-120 days), making early discharge an unlikely reason for missing later ultrasonographic changes. In addition, the infants with diplegia who had cystic lesions also had developmental delay. Only one of the 10 diplegic infants whose pictures did not show cysts had developmental delay at follow up.

Visual defects occurred in 12 infants. When these were due to severe retinopathy of prematurity some periventricular bleeding was always seen, but none of the infants had extensive late cystic lesions. In all six infants with presumed cortical blindness extensive cystic lesions were present. Retinopathy may be associated with free blood in the central nervous system, which produces local vasospasm and retinal injury in much the same way as early ventricular haemorrhage may lead to later ischaemic lesions. Cortical blindness is caused by extensive disruption of tracts and has been described in association with bilateral subcortical cystic lesions. ${ }^{67}$

Bilateral severe deafness was present in 11 infants and was usually associated with extensive peri- 
ventricular haemorrhage, though not necessarily later cystic lesions. Such an association has been described previously and was attributed to blood entering the inner ear. ${ }^{15}$ Convulsions without fever occurred in 12 infants, all of whom had cystic parenchymal lesions or post haemorrhagic hydrocephalus.

\section{References}

' Bejar R, Curbelo V, Coen RW, Leopold G, James H, Gluck L. Diagnosis and follow-up of intraventricular and intracerebellar haemorrhages by ultrasound studies of infants brain through the fontanelles and sutures. Pediatrics, 1980;66:661-73.

2 Stewart AL. Thorburn RJ, Hope PL, Goldsmith M, Lipscomb AP, Reynolds EOR. Ultrasound appearances of the brain in very preterm infants and neurodevelopmental outcome at 18 months of age. Arch Dis Child 1983;58:598-604.

3 Papile L, Munsick-Bruno G, Schaefer A. Relationship of early cerebral intraventricular hemorrhage and early childhood neurologic handicaps. J Pediatr 1983;103:273-6.

${ }^{4}$ Shankaran S, Slovis TL, Bedard MP. Poland RL. Sonographic classification of intracranial hemorrhage. A prognostic indicator of mortality, morbidity, and short-term neurologic outcome. J Pediatr 1982;100:469-75.

5 Ment LR, Scott DT, Ehrenkrantz RA, Rothman SG, Duncan $\mathrm{CC}$, Warshaw JB. Neonates of $<1250 \mathrm{~g}$ birthweight. Prospective neurodevelopmental evaluation during the first year postterm. Pediatrics 1982;70:292-6.

6 Weindling AM, Rochefort MJ, Calvert SA, Fok TF, Wilkinson A. Development of cerebral palsy after ultrasonographic detection of periventricular cysts in the newborn. Dev Med Child Neurol 1985;27:800-6.

${ }^{7}$ de Vries LS, Dubowitz LMS, Dubowitz v, et al. Predictive value of cranial ultrasound in the newborn baby: a reappraisal. Lancet 1985;ii:137-40.

${ }^{x}$ Pape KE, Blackwell RJ, Cusick G. Ultrasound detection of brain damage in preterm infants. Lancet 1979;i:1261-4.

9 Thorburn RJ, Lipscomb AP. Stewart AL, Reynolds EOR. Hope PL. Timing and antecedents of periventricular hacmorrhage and of cerebral atrophy in very preterm infants. Early Hum Dev 1982;7:221-38.

16) Cooke RWI. Factors associated with periventricular haemorrhage in very low birthweight infants. Arch Dis Child 1981:56: 425-31.

1 Thorburn RJ, Lipscomb AP, Stewart AL, Reynolds EOR, Hope PL, Pape KE. Prediction of death and major handicap in very preterm infants by brain ultrasound. Lancet 1981;i: 1119-21.

12 Catto-Smith AG, Yu VYH, Bajuk B, Orgill AA, Astbury J. Effect of neonatal periventricular hacmorrhage on neurodevelopmental outcome. Arch Dis Child 1985;60:8-11.

13 Palmer P, Dubowitz LMS, Levene MI, Dubowitz V. Developmental and neurological progress of preterm infants with intraventricular haemorrhage and ventricular dilatation. Arch Dis Child 1982;57:748-53.

14 Volpe JJ, Herscovitch P, Perlman JM, Raichle ME. Positron emission tomography in the newborn: extensive impairment of regional cerebral bloodflow with intraventricular hemorrhage and hemorrhagic intracerebral involvement. Pediatrics 1983;72: 589-601.

15 Spector GJ, Pettit WJ, Davis G, Strauss M, Rausbach E. Fetal respiratory distress causing CNS and inner ear hemorrhage. Laryngoscope 1978;88:764-84.

Correspondence to Dr R W I Cooke, Department of Child Health, University of Liverpool, Regional Neonatal Intensive Care Unit, Liverpool Maternity Hospital, Liverpool L7 7BN.

Received 6 April 1987 